\title{
Structure reveals the activation mechanism of the MC4 receptor to initiate satiation signaling
}

\author{
Hadar Israeli1,2中, Oksana Degtjarik' ${ }^{1}$, Fabrizio Fierro ${ }^{3,4}$, Vidicha Chunilal' ${ }^{5}$, Amandeep Kaur Gill5, Nicolas J. Roth $^{5}$, \\ Joaquin Botta ${ }^{5}$, Vadivel Prabahar ${ }^{1}$, Yoav Peleg ${ }^{6}$, Li F. Chan $^{5}$, Danny Ben-Zvi²*, Peter J. McCormick ${ }^{5 *}$, \\ Masha Y. Niv ${ }^{3,4 *}$, Moran Shalev-Benami* ${ }^{*}$ \\ 'Department of Chemical and Structural Biology, Weizmann Institute of Science, Rehovot 7610001, Israel. '2Department of Developmental Biology and Cancer Research, The \\ Institute for Medical Research Israel-Canada, The Hebrew University-Hadassah Medical School, Jerusalem, Israel. ${ }^{3}$ The Faculty of Agriculture, Food and Environment, The \\ Hebrew University, Rehovot, Israel. ${ }^{4}$ The Fritz Haber Center for Molecular Dynamics, The Hebrew University, Jerusalem, Israel. ${ }^{5}$ Centre for Endocrinology, William Harvey \\ Research Institute, Barts and the London School of Medicine, Queen Mary, University of London, Charterhouse Square, London, UK. ${ }^{6}$ Structural Proteomics Unit (SPU), Life \\ Sciences Core Facilities (LSCF), Weizmann Institute of Science, Rehovot 7610001, Israel. \\ †These authors contributed equally to this work. ‡Present address: Sosei-Heptares, Cambridge, UK. *Corresponding author. Email: moransb@weizmann.ac.il (M.S.-B.); \\ p.mccormick@qmul.ac.uk (P.J.M.); masha.niv@mail.huji.ac.il (M.Y.N.); danny.ben-zvi@mail.huji.ac.il (D.B.-Z.) \\ Obesity is a global epidemic causing morbidity and impaired quality of life. The melanocortin receptor 4 \\ (MC4R) is at the crux of appetite, energy homeostasis, and body-weight control in the central nervous system \\ and is a prime target for anti-obesity drugs. Here, we present the cryo-EM structure of the human MC4R-G \\ signaling complex bound to the agonist setmelanotide, a cyclic peptide recently approved for the treatment of \\ obesity. The work reveals the mechanism of MC4R activation, highlighting a molecular switch that initiates \\ satiation signaling. In addition, our findings indicate that $\mathrm{Ca}^{2+}$ is required for agonist but not antagonist \\ efficacy. These results fill a gap in understanding MC4R activation and could guide the design of future \\ weight management drugs.
}

Obesity is a global epidemic, with more than $40 \%$ of the adult population considered overweight or obese (1). Obesity is a major risk factor for chronic diseases, including type 2 diabetes, coronary artery disease, and cancer, and constitutes an important cause of morbidity and impaired quality of life (2). Over the years, various weight-loss-targeting drugs have been developed, yet most of these were ultimately removed from the market due to questionable efficacy, lack of target specificity, or severe adverse effects. This highlights the need for a better understanding of the molecular mechanisms governing weight regulation and its related pathologies.

Melanocortin 4 receptor (MC4R) is a member of the melanocortin receptor family (MCRs), a class-A G-protein coupled receptor (GPCR) subgroup consisting of five subtypes (MCR1-5) that mediate multiple physiological effects in humans (3). MC4R is abundant throughout the mammalian central nervous system (CNS) and is expressed in particular within the paraventricular nucleus (PVN) of the hypothalamus, a region critical for energy homeostasis (4-6). MC4R has been shown to play a key role in modulating satiety in pharmacological and genetic studies in animal models and patients (7-9). Loss-of-function mutations in MC4R have been implicated in $\sim 6-8 \%$ of early-onset severe obesity cases and are considered the most common form of monogenic obesity $(7,10)$, while gain-of-function mutations have been linked to low body mass index (BMI) (9). Beyond its critical role in the regulation of food intake and energy expenditure, MC4R also functions in other CNS regions with clinical implications in pain sensation, sexual function, anhedonia, and blood pressure regulation (11-13).

MC4R is an unusual GPCR as it has both an endogenous agonist and an endogenous antagonist $(14,15)$. For other GPCRs, with the exception of the close MC4R homolog MC3R (3), only endogenous agonists have been described. Specifically, MC4R is activated by the alpha-melanocyte-stimulating hormone ( $\alpha$ $\mathrm{MSH}$ ), a proopiomelanocortin (POMC) derived peptide, which mediates anorexigenic effects, and is antagonized through binding of the agouti-related peptide (AgRP), which promotes appetite (14). A recent crystal structure of MC4R bound to a potent antagonist provided a snapshot of the inactive receptor conformation (16), but the molecular architecture of an active complex with cognate signaling partners remained unknown. We determined the structure of the active human MC4R bound to the cyclic peptide agonist setmelanotide and in complex with the $\mathrm{G}_{\mathrm{s}}$ heterotrimer at $3 \AA$ resolution by cryo-EM. Setmelanotide (Imcivree) is a promising weight control drug shown to induce weight loss in patients suffering from POMC deficiency $(17,18)$, leptin receptor deficiency (19) and other forms of severe genetic obesity, and was recently registered by the FDA for the treatment of these conditions (20-23).

The molecular architecture of the native MC4R signaling complex

The setmelanotide-MC4R- $\mathrm{G}_{\mathrm{s}}$ complex was assembled by 
supplying agonist to cells co-expressing heterotrimeric $\mathrm{G}_{\mathrm{s}}$ and full-length MC4R and was stabilized using the single-chain variable fragment scFv16 (24). ScFv16 was originally developed for the stabilization of the $\mathrm{G}_{\mathrm{il}}$ heterotrimer and has been used to determine several $\mathrm{G}_{\mathrm{i} / \mathrm{o}}$ and $\mathrm{G}_{\mathrm{q}}$ GPCR complex structures (25-29). We replaced the $\alpha \mathrm{N}$ helix of $\mathrm{G} \alpha_{\mathrm{s}}$ (residues 1-38) with that of $\mathrm{G}_{\mathrm{i} 1}$ (residues 1-31) to enable complex recognition by scFv16 $\left(\mathrm{G}_{\mathrm{s} \text {-iN }}\right)(24)$. This strategy yielded a stable $\mathrm{G}_{\mathrm{s}}$ heterotrimer that coupled to activated MC4R (fig. S1).

We used single-particle cryo-EM analysis to obtain a three-dimensional reconstruction of the MC4R-G $\mathrm{G}_{\mathrm{s}}$ complex at a nominal resolution of $3 \AA$ (Fig. 1, figs. S1 and S2, and tables $\mathrm{S} 1$ and $\mathrm{S} 2$ ). The map revealed the architectures of all complex components, as well as the mode of receptor association with the $G_{s}$ heterotrimer and the orientation of setmelanotide within the orthosteric binding pocket (Fig. 1, C and D). Most notably, MC4R differs from previously reported class-A GPCR-G-protein complexes in the extracellular region, which is relatively open, containing an exposed cavity of $1082 \AA^{3}$ (Fig. 2, B and C; and fig. S3A). This feature can be attributed to a short extracellular loop 2 (ECL2) that lacks secondary structural elements compared with other class-A members (fig. S3B) (30). As noted previously (16), MC4R lacks a disulfide found in other class-A GPCRs connecting ECL2 with trans-membrane helix 3 (TM3) (31). Instead, the MC4R extracellular region has two other disulfides, which link the $\mathrm{N}$ terminus to TM7, and ECL3 to TM6, both of which are clearly visualized in our EM density $\left(\mathrm{C} 40^{\mathrm{N} \text {-term }}-\mathrm{C} 279^{7.30}\right.$ and $\mathrm{C} 271^{6.61}$ $\mathrm{C} 277^{\mathrm{ECL} 3}$; superscript numbers correspond to the BallesterosWeinstein nomenclature; fig. S2G). Overall, our structure enables the analysis of the full-length, active MC4R coupled with its cognate cellular effectors and supplies residue-resolution information on the main signaling pathway leading to satiety.

\section{Description of setmelanotide in the MC4R binding pocket}

Setmelanotide is a potent mimetic of $\alpha-\mathrm{MSH}$, the endogenous hormone agonist that acts on MC4R to signal satiety and increase energy expenditure (Fig. 2A). Unlike $\alpha-\mathrm{MSH}$, setmelanotide is linked by a disulfide bond between cysteines near its termini. Setmelanotide contains the highly conserved HFRW motif that is shared between all POMC-derived peptides and contributes directly to the activation of receptors of the MCR family (32). However, the phenylalanine in setmelanotide is in the $\mathrm{D}$ configuration, whereas it is in the L conformation in $\alpha-\mathrm{MSH}$ (Fig. 2A).

In the cryo-EM structure, setmelanotide engages MC4R through extensive electrostatic and hydrophobic interactions with residues in the transmembrane domain (Fig. 3A). These interactions are mostly attributed to the HFRW motif and include hydrogen bonds with S188, $\pi-\pi$ stacking interaction with F51, C-H...O contacts (33) with Y268 and F284, and hydrophobic contacts with T101, I129, L133, I185, I194 and F261 (Fig. 3A). Most of these residues are highly conserved among the MCR family and account for the cross reactivity with POMC-derived peptides. Interactions outside the HFRW motif include contacts between $\mathrm{Cys}_{8}$ in setmelanotide and Y268, and F284 in the receptor, only the last of which is conserved in members of the MCR family (Fig. 3B and fig. S4). Additional contacts are from $\mathrm{Arg}_{1}$ and $\mathrm{Ala}_{3}$ to D122 and I104, respectively, both of which are conserved in MCR family members. $\mathrm{Arg}_{1}$ in setmelanotide substitutes for a serine in $\alpha$ MSH and likely contributes to the elevated potency of the drug compared with the endogenous hormone (Fig. 2, A and D).

A notable feature of setmelanotide binding is a $\mathrm{Ca}^{2+}$ ion coordinated by both the agonist and the receptor. $\mathrm{A} \mathrm{Ca}^{2+}$ ion was observed in a similar position in the complex of MC4R with the synthetic antagonist SHU9119 [Fig. 3C and (16)]. In both structures, the receptor contributes the side chains of the acidic residues (D122 $2^{3.25}, \mathrm{D}_{126^{3.29}}$ and $\mathrm{E} 100^{2.60}$ ) to $\mathrm{Ca}^{2+}$ coordination, and both setmelanotide and SHU9119 have a direct interaction to the ion using the $\mathrm{D}-\mathrm{Phe}_{5}$ backbone oxygen (D-naphthyl alanine, D-Nal ${ }_{4}$ in SHU9119, Fig. 3C). One difference in the coordination of the $\mathrm{Ca}^{2+}$ between the antagonist and agonist structures is that SHU9119 contributes the backbone carbonyl of $\mathrm{Asp}_{2}$ in a backbone-ligand interaction, whereas setmelanotide uses a water-mediated interaction between the backbone carbonyl of D-Ala ${ }_{3}$ and the ion (Fig. 3C and fig. S2F). Molecular dynamics simulations suggest that the backbone carbonyl of $\mathrm{Cys}_{2}$ may alternate with the backbone carbonyl of $\mathrm{D}-\mathrm{Ala}_{3}$ in creating the water-mediated interaction (fig. S5, A and B).

\section{$\mathrm{Ca}^{+2}$ functions as a cofactor required for receptor activation but not inhibition}

Molecular dynamics simulations support $\mathrm{Ca}^{2+}$ binding by MC4R even in the absence of a ligand, suggesting that $\mathrm{Ca}^{2+}$ may have a ligand-independent role or may prime the pocket for ligand binding (Fig. 3D and fig. S5, C and D). While the simulations suggest that $\mathrm{Ca}^{2+}$ does not depend on other ligands for binding, MC4R agonists require $\mathrm{Ca}^{2+}$ to achieve full efficacy. The $\mathrm{EC}_{50}$ for both $\alpha-\mathrm{MSH}$ and setmelanotide decreased by about two orders of magnitude in the presence of physiological $\mathrm{Ca}^{2+}$ concentrations $(1 \mathrm{mM})$ in our cellular assays (Fig. 4, A and B; and fig. S6). Indeed, an estimation of a $\mathrm{K}_{\mathrm{B}}$ for $\mathrm{Ca}^{2+}\left(0.06 \mu \mathrm{M}\right.$, fig. S6M) supports $\mathrm{Ca}^{2+}$ binding at physiologic levels to MC4R. Notably, other divalent ions did not have similar effects, nor did we detect allosteric effects on $\mathrm{Ca}^{2+}$ binding caused by the presence of other ions (fig. S6, A to $\mathrm{J})$. These results are in accordance with several previous reports that $\alpha-\mathrm{MSH}$ as well as synthetic agonists depend on the presence of $\mathrm{Ca}^{2+}$ for signaling, with no significant change 
in response to other ions $(16,34)$. We also found that the nonpeptide synthetic MC4R agonist THIQ, depends on $\mathrm{Ca}^{2+}$ for enhanced activity and binding (fig. S7).

In contrast, we found that physiological $\mathrm{Ca}^{2+}$ concentrations do not contribute to inverse-agonist activity of SHU9119, nor to AgRP-induced antagonistic activity. Signaling assays revealed that physiological $\mathrm{Ca}^{2+}$ concentrations do not significantly impact the ability of SHU9119 to compete with $\alpha-\mathrm{MSH}$, and that AgRP activity is in fact hampered by the presence of $\mathrm{Ca}^{2+}$ (Fig. 4, C and D). This suggests that $\mathrm{Ca}^{2+}$ plays a role in modulating receptor susceptibility to endogenous agonists and antagonists.

Notably, one of the residues that was found to coordinate $\mathrm{Ca}^{+2}$ positioning within the binding pocket and modulate ligand accommodation in the receptor, D122 $2^{3.25}$, corresponds to a conserved cysteine residue in other class-A members, which composes a disulfide bridge missing in MCRs (fig. S8, A to C). These data highlight the possibility that $\mathrm{Ca}^{+2}$ serves as a surrogate to the function of the bridge and contributes to the structural integrity of the canonical binding pocket. Given the opposite effect of $\mathrm{Ca}^{2+}$ on the endogenous agonist and antagonist, we suggest that $\mathrm{Ca}^{2+}$ can provide MC4R sufficient flexibility to modulate the binding pocket to differentially accommodate agonists and antagonists.

\section{Mutation of residues involved in $\mathrm{Ca}^{2+}$ coordination reduces receptor activation}

Mutational studies were conducted to further explore the function of $\mathrm{Ca}^{2+}$ coordination in receptor activity and to assess the implications for human disease. Two of the $\mathrm{Ca}^{2+}$ coordinating residues, D122N and D126Y, are naturally occurring mutations associated with obesity $(18,35)$. An E100A mutation was introduced to probe the function of the third $\mathrm{Ca}^{2+}$ coordinating side chain. The D122N mutant displayed a two-log increase in $\mathrm{EC}_{50}$ and $\sim 50 \%$ decrease in efficacy for $\alpha$-MSH and setmelanotide under physiological $\mathrm{Ca}^{2+}$ concentrations. For the E100A mutant, the impairment was not the same for the natural and artificial agonists. While $\alpha$ MSH signaling was almost completely abolished by the E100A mutation, setmelanotide was still able to signal, but at half maximum and with a two-log increase in $\mathrm{EC}_{50}$ (Fig. 4, $\mathrm{E}$ and F). The D126Y mutant resulted in the complete abolishment of receptor function. The more pronounced effect of the D126 substitution can be explained by the fact that D122 and E100 each contribute a single bond to $\mathrm{Ca}^{2+}$ coordination, whereas D126 contributes two (Fig. 3C). Both the D122N and E100A mutants remained dependent on $\mathrm{Ca}^{2+}$ for signaling for both setmelanotide and $\alpha$-MSH, suggesting that altering the aspartates at these positions did not eliminate $\mathrm{Ca}^{2+}$ coordination (fig. S8, E and F). Flow cytometry analysis indicated similar profiles of surface expression levels for wild-type and mutant receptors, indicating that the observed activity changes were not due to poor cell surface availability (fig. S8D). These results are in agreement with previously reported work in which mutations at positions 122 and 126 in MC4R resulted in impaired ligand binding properties $(18,35-$ 38 ). The differential activation profile of the D122N variant by setmelanotide compared with $\alpha$-MSH, highlights setmelanotide as a potential therapeutic path for individuals harboring a D122N mutation. Discussion of common mutations in $\mathrm{MC} 4 \mathrm{R}$ is further provided in fig. S9.

\section{Identification of a mechanical activation switch in MC4R}

Comparing the inactive and active states of MC4R, the outward displacement of TM6 is clearly evident (Fig. 5A and fig. S3C). This structural rearrangement is a hallmark of GPCR activation, allowing the C-terminal $\alpha 5$ helix of the $\mathrm{G} \alpha_{\mathrm{s}}$ subunit to engage the receptor core and initiate signaling. In MC4R, binding of the agonist setmelanotide partly resembles the binding of the antagonist SHU9119 (16) (Figs. 2 and 3), raising the question of how the structural change and GPCR activation are induced selectively by the agonist. A noticeable difference between the binding modes of the antagonist and the agonist is that the D-Nal ${ }_{4}$ group of SHU9119, which is bulkier than the $\mathrm{D}^{-\mathrm{Phe}_{5}}$ in setmelanotide, penetrates the binding pocket more deeply and interacts with $\mathrm{L}^{133^{3.36}}$ (Figs. 2, B and $\mathrm{C}$, and $5 \mathrm{~B}$ ). L133 $3^{3.36}$ is a key modulator in class-A GPCR activation, as it directly interacts with $\mathrm{W} 258^{6.48}$, which plays a crucial role in TM6 displacement during receptor transition to the active state (31). In the inactive state, $\mathrm{L} 133^{3.36}$ engages the aromatic face of W258 ${ }^{6.48}$, with the two methyl groups facing the $\pi$-electrons and maintaining $\mathrm{CH}-\pi$ contacts (Fig. $5 \mathrm{~B}$ ). In the active conformation, $\mathrm{L}_{133^{3.36}}$ is oriented, with the two methyl groups facing away from W258 ${ }^{6.48}$. As a result, W25 $8^{6.48}$ is free to accommodate an alternate state that allows for the conformational rearrangement of TM6 required for Gprotein coupling (Fig. 5, A and B). This conformational change resembles the classic toggle switch in other GPCRs, where in the inactive state $\mathrm{F}^{3.36}$ stacks upon $\mathrm{W}^{6.48}$ to maintain the inactive receptor, whereas in the active conformation $\mathrm{F}^{3.36}$ rotates and allows the release of $\mathrm{W}^{6.48}$ [e.g., $\mathrm{CB1R}(26,39)$, CB2R (40), and CCR5 (41), Fig. 5C]. Comparison between the agonist- and antagonist- bound structures suggests that while SHU9119 sterically hinders the displacement of L133 ${ }^{3.36}$ toward the active state, the phenyl residue in setmelanotide stabilizes the active state conformation (Fig. 5B).

A challenge in targeting MC4R is to avoid undesired side effects due to cross reactivity with other members of the MCR family (e.g., MC3R and MC1R). Thus, identifying distinct features in the activation mechanism of MC4R is important. $\mathrm{MC1R}$ is a close homolog of MC4R, and cross-reactivity with MC1R is often observed when agonists and antagonists designed for MC4R are used clinically $(18,22)$. Further evidence 
can be seen in patients treated with afamelanotide, an MC1R agonist used for the treatment of erythropoietic protoporphyria, these patients often suffer from decreased appetite due to cross reactivity with MC4R (42). A puzzling observation is that MC4R antagonists such as SHU9119 act as agonists for MC1R (43). Residues in the orthosteric binding pocket of MC4R and MC1R are almost identical, but L133 ${ }^{3.36}$ of the MC4R activation switch is replaced by a methionine, M128 ${ }^{3.36}$, in MC1R (fig. S4). We introduced an L133M mutation into MC4R and confirmed that SHU9119 acts as an agonist for this mutant (fig. S8, G to I). In contrast, we found that AgRP did not activate the mutant receptor, suggesting differences in the binding mode for the endogenous antagonist compared with the synthetic derivative (fig. S8G). Comparing the MC4R structure to structures harboring a 3.36 methionine (e.g., the $\mu$-opioid receptor - MOR1), shows that the rotameric state of

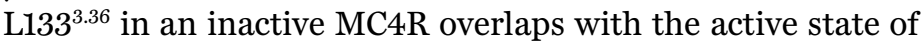
M151 ${ }^{3.36}$ in MOR1 (fig. S8J). Furthermore, superposition of the structure of MC4R bound to SHU9119 with an inactive structure of MOR1 indicates a clash between the naphthyl group in SHU9119 and M151 ${ }^{3.36}$ (fig. S8K). These observations suggest why SHU9119 contributes to agonistic activity in the mutant. These experiments also demonstrate the potential for a selectivity window to reduce the cross reactivity with MC1R that contains a methionine at position 3.36. A full analysis of conserved and synonymous residues in the binding pocket of MCR family members is provided in fig. S4.

\section{Exploring MC4R canonical and non-canonical signaling pathways}

The conventional $\mathrm{G} \alpha_{\mathrm{s}}$ signaling of MC4R is crucial in inducing anorexogenic signaling in the hypothalamus to result in negative energy balance (44-46). However, MC4R can activate other signaling mediators to trigger downstream signaling effects. These include coupling to $\mathrm{G} \alpha_{\mathrm{i}}, \mathrm{G} \alpha_{\mathrm{q}}$, and $\mathrm{G} \alpha_{15}$, interaction with $\beta$-arrestins $(47,48)$, and through G-protein independent coupling to the inwardly rectifying potassium channel Kir7.1 (49). Our work presents the structural mechanistic properties of MC4R activation by setmelanotide and captures the MC4R-G $\mathrm{G}_{\mathrm{s}}$ bound state that allows for the delineation of the coupling interface. The MC4R-G $\alpha_{\mathrm{s}}$ interface is mostly composed of interactions between residues in TM3, TM5 and TM6 at the receptor and the C-terminal helix ( $\alpha 5$ helix) of $\mathrm{G} \alpha_{\mathrm{s}}$ (Fig. $6 \mathrm{~A}$ and fig. S10). These interactions also include a class-A conserved $\pi$-cation stacking between $\mathrm{Y}_{370}{ }^{\mathrm{H} 5.23}$ in $\mathrm{G}_{\mathrm{s}}$, and $\mathrm{R} 147^{3.50}$ in MC4R, where $\mathrm{R}^{3.50}$ composes part of the DRY motif that plays an important role in G-protein coupling (50-54). All residues in MC4R that are involved in $\mathrm{G}_{\mathrm{s}}$ interactions are strictly conserved among all MCR family members, reflecting their shared coupling to $\mathrm{G}_{\mathrm{s}}$ (fig. S4A) (55). In addition, MC4R mutations in residues involved in $\mathrm{G}_{\mathrm{s}}$ recruitment have been associated with impaired signaling through the $\mathrm{G}_{\mathrm{s}}$ pathway and have also been identified in obese individuals $(56,57)$. Notable examples are A219V and T150I, which demonstrate impaired cAMP production without change in binding affinity to $\alpha$-MSH compared with the wild-type receptor $(9,35,58-61)$. A219 $9^{5.65}$ is close to the tip of $\mathrm{G} \alpha_{\mathrm{s}}$ helix $\alpha 5$. Substitution of Ala with a bulkier Val might create a clash that would disturb MC4R-G $\alpha_{\mathrm{s}}$ binding. Residues that interact with $\mathrm{A} 219^{5.65}\left(\mathrm{~L} 367^{\mathrm{H} 5.20}\right.$, L372 ${ }^{\mathrm{H} 5.25}$, and $\mathrm{L} 373^{\mathrm{H} 5.26}$ ) are also conserved in $\mathrm{G}_{\mathrm{q}}$ and $\mathrm{G}_{15}$, both reported to bind $\mathrm{MC} 4 \mathrm{R}$ $(47,62)$, thus mutations at this position, might also interfere with signaling through alternative pathways for this receptor. T150 3.53 is located at the tip of TM3 and contributes two hydrogen bonds to the binding interface through direct interactions with H366 and Y370. Substitution of Thr by hydrophobic Ile would abolish one of the hydrogen bonds, thus impairing recruitment of the $\mathrm{G} \alpha$ subunit.

A recent genetic variant study showed that mutations in MC4R observed in patients with low BMI were associated with MC4R gain-of-function through biased $\beta$-arrestin 2 recruitment to the receptor. These studies highlight the importance of targeting preferred pathways by drugs to treat obesity (9). Analysis of mutations associated with gain-offunction or loss of function of MC4R is provided in fig. S9. Comparing setmelanotide and $\alpha-\mathrm{MSH}$ ability to recruit $\mathrm{G} \alpha_{\mathrm{s}}$ or $\beta$-arrestin 2, we saw no bias toward these two pathways (Fig. $6, \mathrm{~B}$ and $\mathrm{C}$ ). Thus our studies suggest that for the wild-type receptor, both setmelanotide and $\alpha-\mathrm{MSH}$ will act similarly to activate these pathways.

In summary, this work provides a major leap in our understanding of the molecular basis of MC4R activation and inhibition, ligand specificity, and the contribution of genetic variations to MC4R-related pathologies. Looking forward, this work will set the stage for future efforts to develop novel therapeutic strategies to fight obesity and possibly other weight-regulation disorders.

\section{REFERENCES AND NOTES}

1. World Health Organization, Obesity and overweight; www.who.int/news-room/factsheets/detail/obesity-and-overweight.

2. M. Blüher, Obesity: Global epidemiology and pathogenesis. Nat. Rev. Endocrinol. 15, 288-298 (2019). doi:10.1038/s41574-019-0176-8 Medline

3. K. L. J. Ellacott, R. D. Cone, The central melanocortin system and the integration of short- and long-term regulators of energy homeostasis. Recent Prog. Horm. Res. 59, 395-408 (2004). doi:10.1210/rp.59.1.395 Medline

4. K. G. Mountjoy, M. T. Mortrud, M. J. Low, R. B. Simerly, R. D. Cone, Localization of the melanocortin-4 receptor (MC4-R) in neuroendocrine and autonomic control circuits in the brain. Mol. Endocrinol. 8, 1298-1308 (1994). Medline

5. J. Rossi, N. Balthasar, D. Olson, M. Scott, E. Berglund, C. E. Lee, M. J. Choi, D. Lauzon, B. B. Lowell, J. K. Elmquist, Melanocortin-4 receptors expressed by cholinergic neurons regulate energy balance and glucose homeostasis. Cell Metab. 13, 195-204 (2011). doi:10.1016/i.cmet.2011.01.010 Medline

6. B. P. Shah, L. Vong, D. P. Olson, S. Koda, M. J. Krashes, C. Ye, Z. Yang, P. M. Fuller, J. K. Elmquist, B. B. Lowell, MC4R-expressing glutamatergic neurons in the paraventricular hypothalamus regulate feeding and are synaptically connected to the parabrachial nucleus. Proc. Natl. Acad. Sci. U.S.A. 111, 13193-13198 (2014) doi:10.1073/pnas.1407843111 Medline

7. I. S. Farooqi, J. M. Keogh, G. S. H. Yeo, E. J. Lank, T. Cheetham, S. O'Rahilly, Clinical 
spectrum of obesity and mutations in the melanocortin 4 receptor gene. N. Engl. J. Med. 348, 1085-1095 (2003). doi:10.1056/NEJMoa022050 Medline

8. A. S. Garfield, C. Li, J. C. Madara, B. P. Shah, E. Webber, J. S. Steger, J. N. Campbell, O. Gavrilova, C. E. Lee, D. P. Olson, J. K. Elmquist, B. A. Tannous, M. J. Krashes, B. B. Lowell, A neural basis for melanocortin-4 receptor-regulated appetite. Nat. Neurosci. 18, 863-871 (2015). doi:10.1038/nn.4011 Medline

9. L. A. Lotta, J. Mokrosiński, E. Mendes de Oliveira, C. Li, S. J. Sharp, J. Luan, B. Brouwers, V. Ayinampudi, N. Bowker, N. Kerrison, V. Kaimakis, D. Hoult, I. D. Stewart, E. Wheeler, F. R. Day, J. R. B. Perry, C. Langenberg, N. J. Wareham, I. S. Faroogi, Human gain-of-function MC4R variants show signaling bias and protect against obesity. Cell 177, 597-607.e9 (2019). doi:10.1016/j.cell.2019.03.044 Medline

10. K. K. Alharbi, E. Spanakis, K. Tan, M. J. Smith, M. A. Aldahmesh, S. D. O'Dell, A. A. Sayer, D. A. Lawlor, S. Ebrahim, G. Davey Smith, S. O'Rahilly, S. Farooqi, C. Cooper, D. I. W. Phillips, I. N. M. Day, Prevalence and functionality of paucimorphic and private MC4R mutations in a large, unselected European British population, scanned by meltMADGE. Hum. Mutat. 28, 294-302 (2007). doi:10.1002/humu.20404 Medline

11. L. H. T. Van der Ploeg, W. J. Martin, A. D. Howard, R. P. Nargund, C. P. Austin, X. Guan, J. Drisko, D. Cashen, I. Sebhat, A. A. Patchett, D. J. Figueroa, A. G. DiLella, B. M. Connolly, D. H. Weinberg, C. P. Tan, O. C. Palyha, S. S. Pong, T. MacNeil, C. Rosenblum, A. Vongs, R. Tang, H. Yu, A. W. Sailer, T. M. Fong, C. Huang, M. R. Tota, R. S. Chang, R. Stearns, C. Tamvakopoulos, G. Christ, D. L. Drazen, B. D. Spar, R. J. Nelson, D. E. Maclntyre, A role for the melanocortin 4 receptor in sexual function. Proc. Natl. Acad. Sci. U.S.A. 99, 11381-11386 (2002). doi:10.1073/pnas.172378699 Medline

12. M. Beltramo, M. Campanella, G. Tarozzo, S. Fredduzzi, L. Corradini, A. Forlani, R. Bertorelli, A. Reggiani, Gene expression profiling of melanocortin system in neuropathic rats supports a role in nociception. Brain Res. Mol. Brain Res. 118, 111118 (2003). doi:10.1016/i.molbrainres.2003.08.001 Medline

13. B. K. Lim, K. W. Huang, B. A. Grueter, P. E. Rothwell, R. C. Malenka, Anhedonia requires $M C 4 R$-mediated synaptic adaptations in nucleus accumbens. Nature 487, 183-189 (2012). doi:10.1038/nature11160 Medline

14. M. M. Ollmann, B. D. Wilson, Y. K. Yang, J. A. Kerns, Y. Chen, I. Gantz, G. S. Barsh, Antagonism of central melanocortin receptors in vitro and in vivo by agoutirelated protein. Science 278, 135-138 (1997). doi:10.1126/science.278.5335.135 Medline

15. I. Suzuki, A. Tada, M. M. Ollmann, G. S. Barsh, S. Im, M. L. Lamoreux, V. J. Hearing, J. J. Nordlund, Z. A. Abdel-Malek, Agouti signaling protein inhibits melanogenesis and the response of human melanocytes to $\alpha$-melanotropin. J. Invest. Dermatol. 108, 838-842 (1997). doi:10.1111/1523-1747.ep12292572 Medline

16. J. Yu, L. E. Gimenez, C. C. Hernandez, Y. Wu, A. H. Wein, G. W. Han, K. McClary, S. R. Mittal, K. Burdsall, B. Stauch, L. Wu, S. N. Stevens, A. Peisley, S. Y. Williams, V. Chen, G. L. Millhauser, S. Zhao, R. D. Cone, R. C. Stevens, Determination of the melanocortin-4 receptor structure identifies $\mathrm{Ca}^{2+}$ as a cofactor for ligand binding. Science 368, 428-433 (2020). doi:10.1126/science.aaz8995 Medline

17. P. Kühnen, K. Clément, S. Wiegand, O. Blankenstein, K. Gottesdiener, L. L. Martini, K. Mai, U. Blume-Peytavi, A. Grüters, H. Krude, Proopiomelanocortin deficiency treated with a melanocortin-4 receptor agonist. N. Engl. J. Med. 375, 240-246 (2016). doi:10.1056/NEJMoa1512693 Medline

18. T. H. Collet, B. Dubern, J. Mokrosinski, H. Connors, J. M. Keogh, E. Mendes de Oliveira, E. Henning, C. Poitou-Bernert, J. M. Oppert, P. Tounian, F. Marchelli, R. Alili, J. Le Beyec, D. Pépin, J. M. Lacorte, A. Gottesdiener, R. Bounds, S. Sharma, C. Folster, B. Henderson, S. O'Rahilly, E. Stoner, K. Gottesdiener, B. L. Panaro, R. D. Cone, K. Clément, I. S. Farooqi, L. H. T. Van der Ploeg, Evaluation of a melanocortin-4 receptor (MC4R) agonist (Setmelanotide) in MC4R deficiency. Mol. Metab. 6, 1321-1329 (2017). doi:10.1016/i.molmet.2017.06.015 Medline

19. K. Clément, H. Biebermann, I. S. Faroogi, L. Van der Ploeg, B. Wolters, C. Poitou, L. Puder, F. Fiedorek, K. Gottesdiener, G. Kleinau, N. Heyder, P. Scheerer, U. BlumePeytavi, I. Jahnke, S. Sharma, J. Mokrosinski, S. Wiegand, A. Müller, K. Weiß, K. Mai, J. Spranger, A. Grüters, O. Blankenstein, H. Krude, P. Kühnen, MC4R agonism promotes durable weight loss in patients with leptin receptor deficiency. Nat. Med. 24, 551-555 (2018). doi:10.1038/s41591-018-0015-9 Medline

20. K. Clément, E. van den Akker, J. Argente, A. Bahm, W. K. Chung, H. Connors, K. De Waele, I. S. Farooqi, J. Gonneau-Lejeune, G. Gordon, K. Kohlsdorf, C. Poitou, L.
Puder, J. Swain, M. Stewart, G. Yuan, M. Wabitsch, P. Kühnen, Setmelanotide POMC and LEPR Phase 3 Trial Investigators, Efficacy and safety of setmelanotide, an MC4R agonist, in individuals with severe obesity due to LEPR or POMC deficiency: Single-arm, open-label, multicentre, phase 3 trials. Lancet Diabetes Endocrinol. 8, 960-970 (2020). doi:10.1016/S2213-8587(20)30364-8 Medline

21. U.S. Food and Drug Administration, "FDA approves first treatment for weight management for people with certain rare genetic conditions," 27 November 2020; www.fda.gov/drugs/drug-safety-and-availability/fda-approves-first-treatmentweight-management-people-certain-rare-genetic-conditions.

22. R. Haws, S. Brady, E. Davis, K. Fletty, G. Yuan, G. Gordon, M. Stewart, J. Yanovski, Effect of setmelanotide, a melanocortin-4 receptor agonist, on obesity in BardetBiedl syndrome. Diabetes Obes. Metab. 22, 2133-2140 (2020). doi:10.1111/dom.14133 Medline

23. A. Markham, Setmelanotide: First approval. Drugs 81, 397-403 (2021). doi:10.1007/s40265-021-01470-9 Medline

24. S. Maeda, A. Koehl, H. Matile, H. Hu, D. Hilger, G. F. X. Schertler, A. Manglik, G. Skiniotis, R. J. P. Dawson, B. K. Kobilka, Development of an antibody fragment that stabilizes GPCR/G-protein complexes. Nat. Commun. 9, 3712 (2018). doi:10.1038/s41467-018-06002-w Medline

25. A. Koehl, H. Hu, S. Maeda, Y. Zhang, Q. Qu, J. M. Paggi, N. R. Latorraca, D. Hilger, R. Dawson, H. Matile, G. F. X. Schertler, S. Granier, W. I. Weis, R. O. Dror, A. Manglik, G. Skiniotis, B. K. Kobilka, Structure of the $\mu$-opioid receptor-Gi protein complex. Nature 558, 547-552 (2018). doi:10.1038/s41586-018-0219-7 Medline

26. K. Krishna Kumar, M. Shalev-Benami, M. J. Robertson, H. Hu, S. D. Banister, S. A. Hollingsworth, N. R. Latorraca, H. E. Kato, D. Hilger, S. Maeda, W. I. Weis, D. L. Farrens, R. O. Dror, S. V. Malhotra, B. K. Kobilka, G. Skiniotis, Structure of a signaling cannabinoid receptor 1-G protein complex. Cell 176, 448-458.e12 (2019). doi:10.1016/i.cell.2018.11.040 Medline

27. S. Maeda, Q. Qu, M. J. Robertson, G. Skiniotis, B. K. Kobilka, Structures of the M1 and M2 muscarinic acetylcholine receptor/G-protein complexes. Science 364 , 552-557 (2019). doi:10.1126/science.aaw5188 Medline

28. K. Kim, T. Che, O. Panova, J. F. DiBerto, J. Lyu, B. E. Krumm, D. Wacker, M. J. Robertson, A. B. Seven, D. E. Nichols, B. K. Shoichet, G. Skiniotis, B. L. Roth, Structure of a hallucinogen-activated Gq-coupled $5-\mathrm{HT}_{2 \mathrm{~A}}$ serotonin receptor. Cell 182, 1574-1588.e19 (2020). doi:10.1016/i.cell.2020.08.024 Medline

29. J. Yin, K. M. Chen, M. J. Clark, M. Hijazi, P. Kumari, X. C. Bai, R. K. Sunahara, P. Barth, D. M. Rosenbaum, Structure of a D2 dopamine receptor-G-protein complex in a lipid membrane. Nature 584, 125-129 (2020). doi:10.1038/s41586020-2379-5 Medline

30. B. Holst, T. W. Schwartz, Molecular mechanism of agonism and inverse agonism in the melanocortin receptors: $\mathrm{Zn}^{2+}$ as a structural and functional probe. Ann. $\mathrm{N}$. Y. Acad. Sci. 994, 1-11 (2003). doi:10.1111/i.1749-6632.2003.tb03156.x Medline

31. A. J. Venkatakrishnan, X. Deupi, G. Lebon, C. G. Tate, G. F. Schertler, M. M. Babu, Molecular signatures of G-protein-coupled receptors. Nature 494, 185-194 (2013). doi:10.1038/nature11896 Medline

32. J. P. L. Gonçalves, D. Palmer, M. Meldal, MC4R agonists: Structural overview on antiobesity therapeutics. Trends Pharmacol. Sci. 39, 402-423 (2018). doi:10.1016/j.tips.2018.01.004 Medline

33. L. Jiang, L. Lai, $\mathrm{CH} \cdots 0$ hydrogen bonds at protein-protein interfaces. J. Biol. Chem. 277, 37732-37740 (2002). doi:10.1074/jbc.M204514200 Medline

34. R. Link, S. Veiksina, M. J. Tahk, T. Laasfeld, P. Paiste, S. Kopanchuk, A. Rinken, The constitutive activity of melanocortin- 4 receptors in cAMP pathway is allosterically modulated by zinc and copper ions. J. Neurochem. 153, 346-361 (2020). doi:10.1111/inc.14933 Medline

35. F. Stutzmann, K. Tan, V. Vatin, C. Dina, B. Jouret, J. Tichet, B. Balkau, N. Potoczna, F. Horber, S. O'Rahilly, I. S. Farooqi, P. Froguel, D. Meyre, Prevalence of melanocortin-4 receptor deficiency in Europeans and their age-dependent penetrance in multigenerational pedigrees. Diabetes 57, 2511-2518 (2008). do: $10.2337 / \mathrm{db} 08-0153$ Medline

36. Z. Q. Wang, Y. X. Tao, Functional studies on twenty novel naturally occurring melanocortin-4 receptor mutations. Biochim. Biophys. Acta 1812, 1190-1199 (2011). doi:10.1016/i.bbadis.2011.06.008 Medline

37. B. A. Fleck, C. Chen, W. Yang, R. Huntley, S. Markison, S. A. Nickolls, A. C. Foster, S. R. J. Hoare, Molecular interactions of nonpeptide agonists and antagonists with the melanocortin-4 receptor. Biochemistry 44, 14494-14508 (2005). 
doi:10.1021/bi051316s Medline

38. Y. K. Yang, T. M. Fong, C. J. Dickinson, C. Mao, J. Y. Li, M. R. Tota, R. Mosley, L. H. T. Van Der Ploeg, I. Gantz, Molecular determinants of ligand binding to the human melanocortin-4 receptor. Biochemistry 39, 14900-14911 (2000). doi:10.1021/bi001684a Medline

39. S. D. McAllister, D. P. Hurst, J. Barnett-Norris, D. Lynch, P. H. Reggio, M. E. Abood, Structural mimicry in class A G protein-coupled receptor rotamer toggle switches: The importance of the F3.36(201)/W6.48(357) interaction in cannabinoid $\mathrm{CB}_{1}$ receptor activation. J. Biol. Chem. 279, 48024-48037 (2004). doi:10.1074/jbc.M406648200 Medline

40. X. Li, T. Hua, K. Vemuri, J. H. Ho, Y. Wu, L. Wu, P. Popov, O. Benchama, N. Zvonok, K. Locke, L. Qu, G. W. Han, M. R. Iyer, R. Cinar, N. J. Coffey, J. Wang, M. Wu, V. Katritch, S. Zhao, G. Kunos, L. M. Bohn, A. Makriyannis, R. C. Stevens, Z. J. Liu, Crystal structure of the human cannabinoid receptor CB2. Cell 176, 459-467.e13 (2019). doi:10.1016/i.cell.2018.12.011 Medline

41. Q. Tan, Y. Zhu, J. Li, Z. Chen, G. W. Han, I. Kufareva, T. Li, L. Ma, G. Fenalti, J. Li, W. Zhang, X. Xie, H. Yang, H. Jiang, V. Cherezov, H. Liu, R. C. Stevens, Q. Zhao, B. Wu, Structure of the CCR5 chemokine receptor-HIV entry inhibitor maraviroc complex. Science 341, 1387-1390 (2013). doi:10.1126/science.1241475 Medline

42. E. I. Minder, J. Barman-Aksoezen, X. Schneider-Yin, Pharmacokinetics and pharmacodynamics of afamelanotide and its clinical use in treating dermatologic disorders. Clin. Pharmacokinet. 56, 815-823 (2017). doi:10.1007/s40262-0160501-5 Medline

43. Y. Yang, M. Chen, Y. Lai, I. Gantz, K. E. Georgeson, C. M. Harmon, Molecular determinants of human melanocortin-4 receptor responsible for antagonist SHU9119 selective activity. J. Biol. Chem. 277, 20328-20335 (2002) doi:10.1074/ibc.M201343200 Medline

44. Y. Minokoshi, T. Alquier, N. Furukawa, Y. B. Kim, A. Lee, B. Xue, J. Mu, F. Foufelle, P. Ferré, M. J. Birnbaum, B. J. Stuck, B. B. Kahn, AMP-kinase regulates food intake by responding to hormonal and nutrient signals in the hypothalamus. Nature 428 , 569-574 (2004). doi:10.1038/nature02440 Medline

45. K. G. Mountjoy, L. S. Robbins, M. T. Mortrud, R. D. Cone, The cloning of a family of genes that encode the melanocortin receptors. Science 257, 1248-1251 (1992). doi:10.1126/science. 1325670 Medline

46. I. Gantz, H. Miwa, Y. Konda, Y. Shimoto, T. Tashiro, S. J. Watson, J. DelValle, T. Yamada, Molecular cloning, expression, and gene localization of a fourth melanocortin receptor. J. Biol. Chem. 268, 15174-15179 (1993). doi:10.1016/S0021-9258(18)82452-8 Medline

47. C. Avet, A. Mancini, B. Breton, C. Le Gouill, A. Hauser, C. Normand, H. Kobayashi, F. Gross, M. Hogue, V. Lukasheva, S. Morissette, E. Fauman, J.-P. Fortin, S. Schann, X. Leroy, D. E. Gloriam, M. Bouvier, Selectivity landscape of 100 therapeutically relevant GPCR profiled by an effector translocation-based BRET platform. SSRN 3586569 [Preprint]. 15 May 2020; https://doi.org/10.2139/ssrn.3586569.

48. A. Inoue, F. Raimondi, F. M. N. Kadji, G. Singh, T. Kishi, A. Uwamizu, Y. Ono, Y. Shinjo, S. Ishida, N. Arang, K. Kawakami, J. S. Gutkind, J. Aoki, R. B. Russell, Illuminating G-protein-coupling selectivity of GPCRs. Cell 177, 1933-1947.e25 (2019). doi:10.1016/j.cell.2019.04.044 Medline

49. M. Ghamari-Langroudi, G. J. Digby, J. A. Sebag, G. L. Millhauser, R. Palomino, R. Matthews, T. Gillyard, B. L. Panaro, I. R. Tough, H. M. Cox, J. S. Denton, R. D. Cone G-protein-independent coupling of MC4R to Kir7.1 in hypothalamic neurons. Nature 520, 94-98 (2015). doi:10.1038/nature14051 Medline

50. J. Ballesteros, S. Kitanovic, F. Guarnieri, P. Davies, B. J. Fromme, K. Konvicka, L. Chi, R. P. Millar, J. S. Davidson, H. Weinstein, S. C. Sealfon, Functional microdomains in G-protein-coupled receptors. The conserved arginine-cage motif in the gonadotropin-releasing hormone receptor. J. Biol. Chem. 273, 1044510453 (1998). doi:10.1074/jbc.273.17.10445 Medline

51. B. Carpenter, R. Nehmé, T. Warne, A. G. W. Leslie, C. G. Tate, Structure of the adenosine $A_{2 A}$ receptor bound to an engineered $G$ protein. Nature 536, 104-107 (2016). doi:10.1038/nature18966 Medline

52. X. Lin, M. Li, N. Wang, Y. Wu, Z. Luo, S. Guo, G. W. Han, S. Li, Y. Yue, X. Wei, X. Xie, Y. Chen, S. Zhao, J. Wu, M. Lei, F. Xu, Structural basis of ligand recognition and self-activation of orphan GPR52. Nature 579, 152-157 (2020). doi:10.1038/s41586-020-2019-0 Medline

53. G. E. Rovati, V. Capra, R. R. Neubig, The highly conserved DRY motif of class A G protein-coupled receptors: Beyond the ground state. Mol. Pharmacol. 71, 959964 (2007). doi:10.1124/mol.106.029470 Medline

54. L.-K. Yang, Y.-X. Tao, Alanine scanning mutagenesis of the DRYxxl motif and intracellular loop 2 of human melanocortin-4 receptor. Int. J. Mol. Sci. 21, 7611 (2020). doi:10.3390/iims21207611 Medline

55. A. R. Rodrigues, H. Almeida, A. M. Gouveia, Intracellular signaling mechanisms of the melanocortin receptors: Current state of the art. Cell. Mol. Life Sci. 72, 13311345 (2015). doi:10.1007/s00018-014-1800-3 Medline

56. Z. C. Fan, Y. X. Tao, Functional characterization and pharmacological rescue of melanocortin-4 receptor mutations identified from obese patients. J. Cell. Mol. Med. 13, 3268-3282 (2009). doi:10.1111/j.1582-4934.2009.00726x x Medline

57. Y. X. Tao, D. L. Segaloff, Functional analyses of melanocortin- 4 receptor mutations identified from patients with binge eating disorder and nonobese or obese subjects. J. Clin. Endocrinol. Metab. 90, 5632-5638 (2005). doi:10.1210/jc.20050519 Medline

58. L. H. Larsen, S. M. Echwald, T. I. A. Sørensen, T. Andersen, B. S. Wulff, O. Pedersen, Prevalence of mutations and functional analyses of melanocortin 4 receptor variants identified among 750 men with juvenile-onset obesity. J. Clin. Endocrinol. Metab. 90, 219-224 (2005). doi:10.1210/jc.2004-0497 Medline

59. Z. Xiang, B. Proneth, M. L. Dirain, S. A. Litherland, C. Haskell-Luevano, Pharmacological characterization of 30 human melanocortin-4 receptor polymorphisms with the endogenous proopiomelanocortin-derived agonists, synthetic agonists, and the endogenous agouti-related protein antagonist. Biochemistry 49, 4583-4600 (2010). doi:10.1021/bi100068u Medline

60. Z. Xiang, S. A. Litherland, N. B. Sorensen, B. Proneth, M. S. Wood, A. M. Shaw, W. J. Millard, C. Haskell-Luevano, Pharmacological characterization of 40 human melanocortin-4 receptor polymorphisms with the endogenous proopiomelanocortin-derived agonists and the agouti-related protein (AGRP) antagonist. Biochemistry 45, 7277-7288 (2006). doi:10.1021/bi0600300 Medline

61. C. Lubrano-Berthelier, B. Dubern, J. M. Lacorte, F. Picard, A. Shapiro, S. Zhang, S. Bertrais, S. Hercberg, A. Basdevant, K. Clement, C. Vaisse, Melanocortin 4 receptor mutations in a large cohort of severely obese adults: Prevalence, functional classification, genotype-phenotype relationship, and lack of association with binge eating. J. Clin. Endocrinol. Metab. 91, 1811-1818 (2006). doi:10.1210/ic.2005-1411 Medline

62. Y. Q. Li, Y. Shrestha, M. Pandey, M. Chen, A. Kablan, O. Gavrilova, S. Offermanns, L. S. Weinstein, $\mathrm{G}_{\mathrm{q} / 11 \alpha}$ and $\mathrm{G}_{\mathrm{s}} \alpha$ mediate distinct physiological responses to central melanocortins. J. Clin. Invest. 126, 40-49 (2016). doi:10.1172/JCI76348 Medline

63. T. Unger, Y. Jacobovitch, A. Dantes, R. Bernheim, Y. Peleg, Applications of the Restriction Free (RF) cloning procedure for molecular manipulations and protein expression. J. Struct. Biol. 172, 34-44 (2010). doi:10.1016/i.jsb.2010.06.016 Medline

64. S. Q. Zheng, E. Palovcak, J.-P. Armache, K. A. Verba, Y. Cheng, D. A. Agard, MotionCor2: Anisotropic correction of beam-induced motion for improved cryoelectron microscopy. Nat. Methods 14, 331-332 (2017). doi:10.1038/nmeth.4193 Medline

65. A. Rohou, N. Grigorieff, CTFFIND4: Fast and accurate defocus estimation from electron micrographs. J. Struct. Biol. 192, 216-221 (2015). doi:10.1016/i.jsb.2015.08.008 Medline

66. J. Zivanov, T. Nakane, B. O. Forsberg, D. Kimanius, W. J. H. Hagen, E. Lindahl, S. H. $W$. Scheres, New tools for automated high-resolution cryo-EM structure determination in RELION-3. elife 7, e42166 (2018). doi:10.7554/eLife.42166 Medline

67. J. A. Mindell, N. Grigorieff, Accurate determination of local defocus and specimen tilt in electron microscopy. J. Struct. Biol. 142, 334-347 (2003) doi:10.1016/S1047-8477(03)00069-8 Medline

68. G. Tang, L. Peng, P. R. Baldwin, D. S. Mann, W. Jiang, I. Rees, S. J. Ludtke, EMAN2: An extensible image processing suite for electron microscopy. J. Struct. Biol. 157, 38-46 (2007). doi:10.1016/i.jsb.2006.05.009 Medline

69. N. W. Moriarty, R. W. Grosse-Kunstleve, P. D. Adams, electronic Ligand Builder and Optimization Workbench (eLBOW): A tool for ligand coordinate and restraint generation. Acta Crystallogr. D Biol. Crystallogr. 65, 1074-1080 (2009). doi:10.1107/S0907444909029436 Medline

70. E. F. Pettersen, T. D. Goddard, C. C. Huang, G. S. Couch, D. M. Greenblatt, E. C. 
Meng, T. E. Ferrin, UCSF Chimera-A visualization system for exploratory research and analysis. J. Comput. Chem. 25, 1605-1612 (2004). doi:10.1002/icc.20084 Medline

71. P. Emsley, K. Cowtan, Coot: Model-building tools for molecular graphics. Acta Crystallogr. D Biol. Crystallogr. 60, 2126-2132 (2004). doi:10.1107/S0907444904019158 Medline

72. D. Liebschner, P. V. Afonine, M. L. Baker, G. Bunkóczi, V. B. Chen, T. I. Croll, B. Hintze, L.-W. Hung, S. Jain, A. J. McCoy, N. W. Moriarty, R. D. Oeffner, B. K. Poon, M. G. Prisant, R. J. Read, J. S. Richardson, D. C. Richardson, M. D. Sammito, O. V. Sobolev, D. H. Stockwell, T. C. Terwilliger, A. G. Urzhumtsev, L. L. Videau, C. J. Williams, P. D. Adams, Macromolecular structure determination using x-rays, neutrons and electrons: Recent developments in Phenix. Acta Crystallogr. D Struct. Biol. 75, 861-877 (2019). doi:10.1107/S2059798319011471 Medline

73. P. V. Afonine, B. K. Poon, R. J. Read, O. V. Sobolev, T. C. Terwilliger, A. Urzhumtsev, P. D. Adams, Real-space refinement in PHENIX for cryo-EM and crystallography. Acta Crystallogr. D Struct. Biol. 74, 531-544 (2018). doi:10.1107/S2059798318006551 Medline

74. V. B. Chen, W. B. Arendall 3rd, J. J. Headd, D. A. Keedy, R. M. Immormino, G. J. Kapral, L. W. Murray, J. S. Richardson, D. C. Richardson, MolProbity: All-atom structure validation for macromolecular crystallography. Acta Crystallogr. D Biol. Crystallogr. 66, 12-21 (2010). doi:10.1107/S0907444909042073 Medline

75. J. Lee, X. Cheng, J. M. Swails, M. S. Yeom, P. K. Eastman, J. A. Lemkul, S. Wei, J. Buckner, J. C. Jeong, Y. Qi, S. Jo, V. S. Pande, D. A. Case, C. L. Brooks III, A. D. Mackerell Jr., J. B. Klauda, W. Im, CHARMM-GUI input generator for NAMD, Gromacs, Amber, OpenMM, and CHARMM/OpenMM simulations using the CHARMM36 additive force field. Biophys. J. 110, 641a (2016). doi:10.1016/i.bpi.2015.11.3431

76. M. A. Lomize, I. D. Pogozheva, H. Joo, H. I. Mosberg, A. L. Lomize, OPM database and PPM web server: Resources for positioning of proteins in membranes. Nucleic Acids Res. 40, D370-D376 (2012). doi:10.1093/nar/gkr703 Medline

77. M. O. W. Grimm, S. Grösgen, M. Riemenschneider, H. Tanila, H. S. Grimm, T. Hartmann, From brain to food: Analysis of phosphatidylcholins, Iysophosphatidylcholins and phosphatidylcholin-plasmalogens derivates in Alzheimer's disease human post mortem brains and mice model via mass spectrometry. J. Chromatogr. A 1218, 7713-7722 (2011). doi:10.1016/i.chroma.2011.07.073 Medline

78. D. Van Der Spoel, E. Lindahl, B. Hess, G. Groenhof, A. E. Mark, H. J. C. Berendsen, GROMACS: Fast, flexible, and free. J. Comput. Chem. 26, 1701-1718 (2005). doi:10.1002/jcc.20291 Medline

79. J. Huang, S. Rauscher, G. Nawrocki, T. Ran, M. Feig, B. L. de Groot, H. Grubmüller, A. D. MacKerell Jr., CHARMM36: An improved force field for folded and intrinsically disordered proteins. Biophys. J. 112, 175a-176a (2017). doi:10.1016/i.bpj.2016.11.971

80. M. Igaev, C. Kutzner, L. V. Bock, A. C. Vaiana, H. Grubmüller, Automated cryo-EM structure refinement using correlation-driven molecular dynamics. elife 8 , e43542 (2019). doi:10.7554/eLife.43542 Medline

81. W. Humphrey, A. Dalke, K. Schulten, VMD: Visual molecular dynamics. J. Mol. Graph. 14, 33-38 (1996). doi:10.1016/0263-7855(96)00018-5 Medline

82. R. A. Friesner, R. B. Murphy, M. P. Repasky, L. L. Frye, J. R. Greenwood, T. A. Halgren, P. C. Sanschagrin, D. T. Mainz, Extra precision glide: Docking and scoring incorporating a model of hydrophobic enclosure for protein-ligand complexes. J. Med. Chem. 49, 6177-6196 (2006). doi:10.1021/im051256o Medline

83. S. Kim, J. Chen, T. Cheng, A. Gindulyte, J. He, S. He, Q. Li, B. A. Shoemaker, P. A. Thiessen, B. Yu, L. Zaslavsky, J. Zhang, E. E. Bolton, PubChem in 2021: New data content and improved web interfaces. Nucleic Acids Res. 49, D1388-D1395 (2021). doi:10.1093/nar/gkaa971 Medline

84. Schrödinger Release 2021-1: LigPrep (Schrödinger, New York, 2021).

85. G. Madhavi Sastry, M. Adzhigirey, T. Day, R. Annabhimoju, W. Sherman, Protein and ligand preparation: Parameters, protocols, and influence on virtual screening enrichments. J. Comput. Aided Mol. Des. 27, 221-234 (2013). doi:10.1007/s10822-013-9644-8 Medline

86. A. Christopoulos, T. Kenakin, G protein-coupled receptor allosterism and complexing. Pharmacol. Rev. 54, 323-374 (2002). doi:10.1124/pr.54.2.323 Medline

87. M. Landau, I. Mayrose, Y. Rosenberg, F. Glaser, E. Martz, T. Pupko, N. Ben-Tal,
ConSurf 2005: The projection of evolutionary conservation scores of residues on protein structures. Nucleic Acids Res. 33 W299-W302 (2005). doi:10.1093/nar/gki370 Medline

88. K. H. Wade, B. Y. H. Lam, A. Melvin, W. Pan, L. J. Corbin, D. A. Hughes, K. Rainbow, J. H. Chen, K. Duckett, X. Liu, J. Mokrosiński, A. Mörseburg, S. Neaves, A. Williamson, C. Zhang, I. S. Farooqi, G. S. H. Yeo, N. J. Timpson, S. O'Rahilly, Prevalence and expressivity of loss of function mutations in the melanocortin 4 receptor (MC4R) in a UK birth cohort. medRxiv 2020.10.30.20220467 [Preprint]. 3 November 2020; https://doi.org/10.1101/2020.10.30.20220467.

\section{ACKNOWLEDGMENTS}

We thank Dr. Nadav Elad for the technical support in microscope operation. We thank Prof. Deborah Fass and Prof. Amnon Horovitz for their helpful discussions and insights. Funding: This work was funded by the Abisch Frenkel and the Minerva Stiftung Foundations for M.S-B. M.S-B holds the Tauro Career Development Chair in Biomedical Research. M.S-B is supported by the Zuckerman STEM Leadership Program, by Ilse Katz Institute for Material Sciences and Magnetic Resonance Research, the Helen \& Milton A. Kimmelman Center for Biomolecular Structure \& Assembly, the Joseph and Wolf Lebovic Lab, Dov and Ziva Rabinovich Endowed Fund for Structural Biology, the Harmstieg New Scientist Fund, the Pearl Welinsky Merlo Foundation and by Paul and Tina Gardner. H.I. is the recipient of the Glassman fellowship. M.Y.N is supported by ISF grants \#1129/19. F.F is the recipient of S.A. Schonbrunn Fellowship Fund. L.F.C was supported by The Medical Research Council (MRC) UK/Academy of Medical Sciences Clinician Scientist Grant (G0802796). D.B-Z is supported by the Zuckerman STEM Leadership Program. P.J.M was supported by the BBSRC (BB/R006946/1) and MRC (MR/S008608/1). N.R. is funded by an MRC DTP, and V.C. is funded by an MRC-Barts Charity iCase award (MRC0227). M.S-B, M.Y.N. and P.J.M. are members of the EU funded ERNEST COST action CA18133. Author contributions: H.I prepared the MC4R-Gs complex with the help of O.D and under the supervision of M.S-B; P.V purified ScFv16; O.D prepared grids, obtained cryo-EM data, processed data, and modeled the structure under the supervision of M.S-B; Y.P. and M.S-B cloned MC4R constructs, mutants and $G_{s}$ chimera, and optimized conditions for protein expression; F.F performed and analyzed molecular dynamics simulations and docking under the supervision of M.Y.N; J.B, A.G. and V.C performed the CAMP accumulation assays and N.R analyzed the surface expression of receptors by means of flow cytometry analysis under the supervision of P.J.M and L.F.C; M.SB, P.J.M, M.Y.N and D.B-Z conceptualized the study; M.S-B and P.J.M wrote the manuscript with the help of H.I, O.D and F.F. All authors provided input for the final manuscript version. Competing interests: The authors declare no competing interests. Data and materials availability: The cryo-EM density map has been deposited in the Electron Microscopy Data Bank (EMDB) under accession code EMD-11927, and model coordinates have been deposited in the Protein Data Bank (PDB) under accession no. 7AUE. All other data are available in the manuscript or supplementary materials. Materials are available from M.S$B$ and P.J.M. upon request.

\section{SUPPLEMENTARY MATERIALS}

science.sciencemag.org/cgi/content/full/science.abf7958/DC1

Materials and Methods

Figs. S1 to S10

Tables S1 to S5

References (63-88)

MDAR Reproducibility Checklist

19 November 2020; accepted 8 April 2021

Published online 15 April 2021

10.1126/science.abf7958 
A

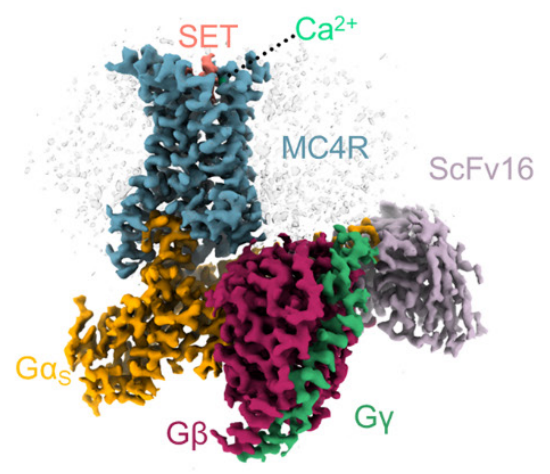

\author{
B
}

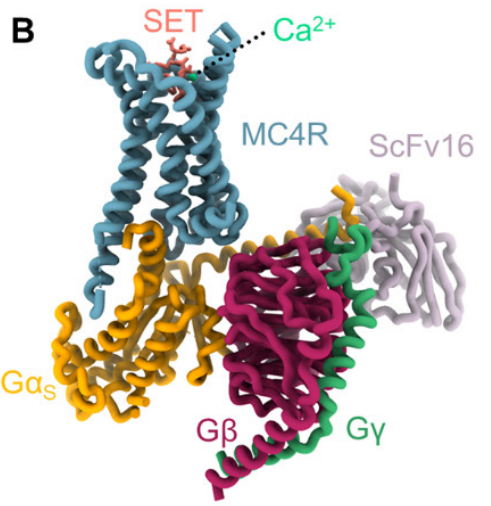

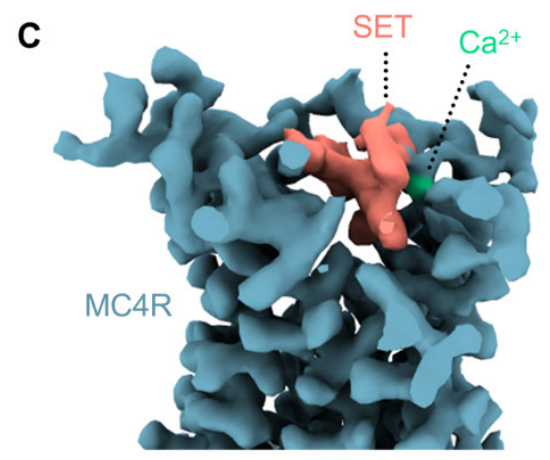

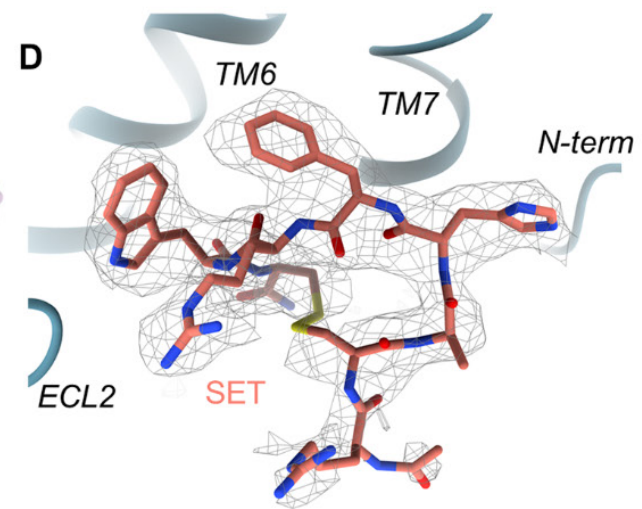

Fig. 1. An overall description of MC4R architecture. (A) Cryo-EM map of the $M C 4 R-G_{s}$ signaling complex embedded within an LMNG:GDN micelle. MC4R is in blue, Setmelanotide (SET) in pink and $\mathrm{G} \alpha_{s}, \beta$ and $\gamma$ are in yellow, magenta and green, respectively. ScFv16 is in light purple. Bottom map is rotated $90^{\circ}$ along the $X$ axis. Map contour level is 0.027. (B) Cartoon model corresponding to map positions presented in (A). (C) A view of MC4R cryo-EM map with setmelanotide in the orthosteric binding pocket. Setmelanotide is in pink, density for $\mathrm{Ca}^{+2}$ is presented in light green. Map contour level is 0.027. (D) Setmelanotide in density. Map contour level is 0.02. 
A

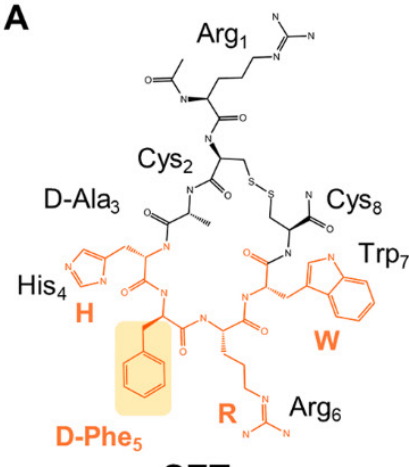

SET

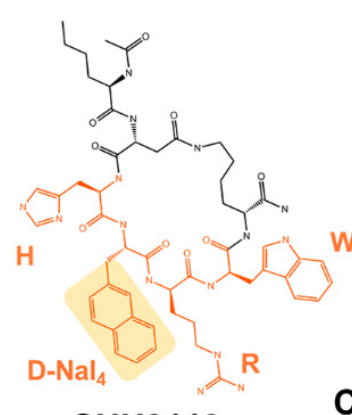

SHU9119

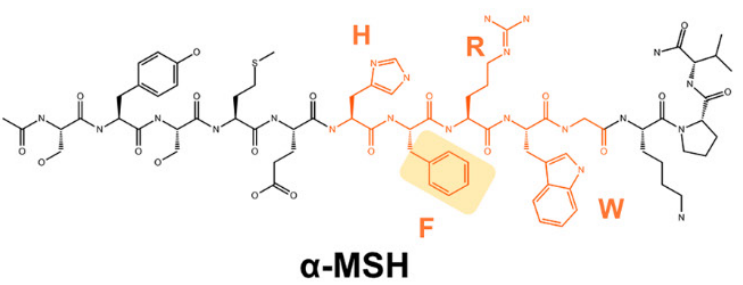

B

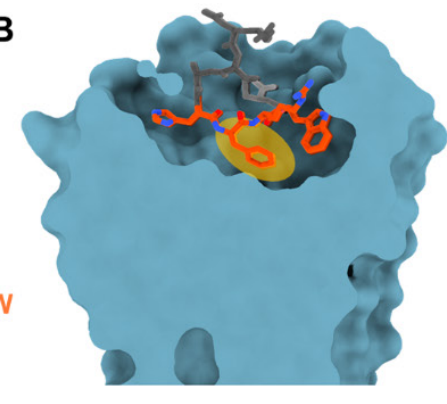

C

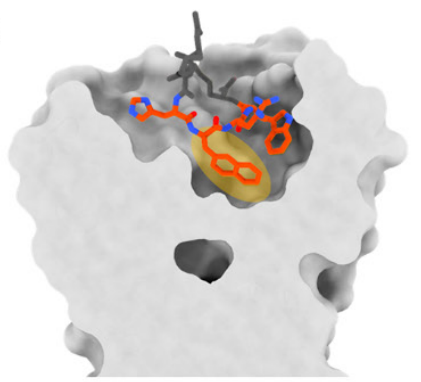

D

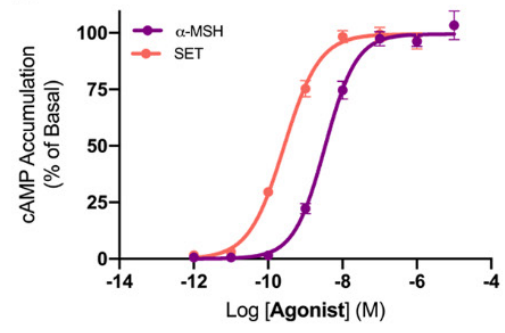

$\mathbf{E}$

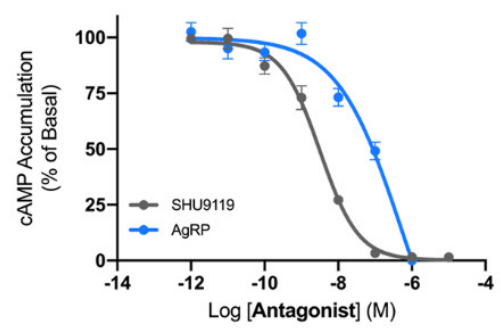

Fig. 2. Agonists and antagonists for MC4R. (A) Chemical structures of MC4R agonists $\alpha-M S H$ and setmelanotide (SET) and the antagonist SHU9119. The conserved HFRW motif is in orange. Phenylalanine substitutions in SET (D-Phe $)$ and in SHU9119 (D-Nal $)_{4}$ are highlighted in yellow. (B and C) A view of setmelanotide (B) and SHU9119 (PDB 6W25) (C) at the MC4R orthosteric binding pocket. HFRW motif is in orange with D-Phe 5 (SET) and D-Nal ${ }_{4}$ (SHU9119) highlighted in yellow. Active receptor is in blue (B) and inactive in grey (C). Comparing the active and inactive receptor states, the D-Nal 4 moiety of the antagonist SHU9119 penetrates more deeply into the pocket. (D) Dose response curves for the agonists $\alpha$-MSH (purple) and setmelanotide (pink) measured as cAMP production normalized by $\%$ basal activity of the wild-type receptor. Data represented as mean \pm SEM from 3 independent experiments done in triplicate, indicating $E_{50}$ values of $3.79 \pm 0.87$ $\mathrm{nM}$ and $0.29 \pm 0.04 \mathrm{nM}$ for $\alpha-\mathrm{MSH}$ and setmelanotide, respectively. (E) Competition assays of inverse agonists AgRP (blue) and SHU9119 (grey) with $\alpha-M S H$, calculated as the decrease in cAMP production in the presence of increasing dose of the antagonists. Experiments were conducted in the presence of $1 \mu \mathrm{M} \alpha-\mathrm{MSH}$. Data represented as mean \pm SEM from 3 independent experiments done in triplicate. plC 50 values are $6.67 \pm 0.18$ and $8.51 \pm 0.05 \mathrm{nM}$ for AgRP and SHU9119, respectively. 

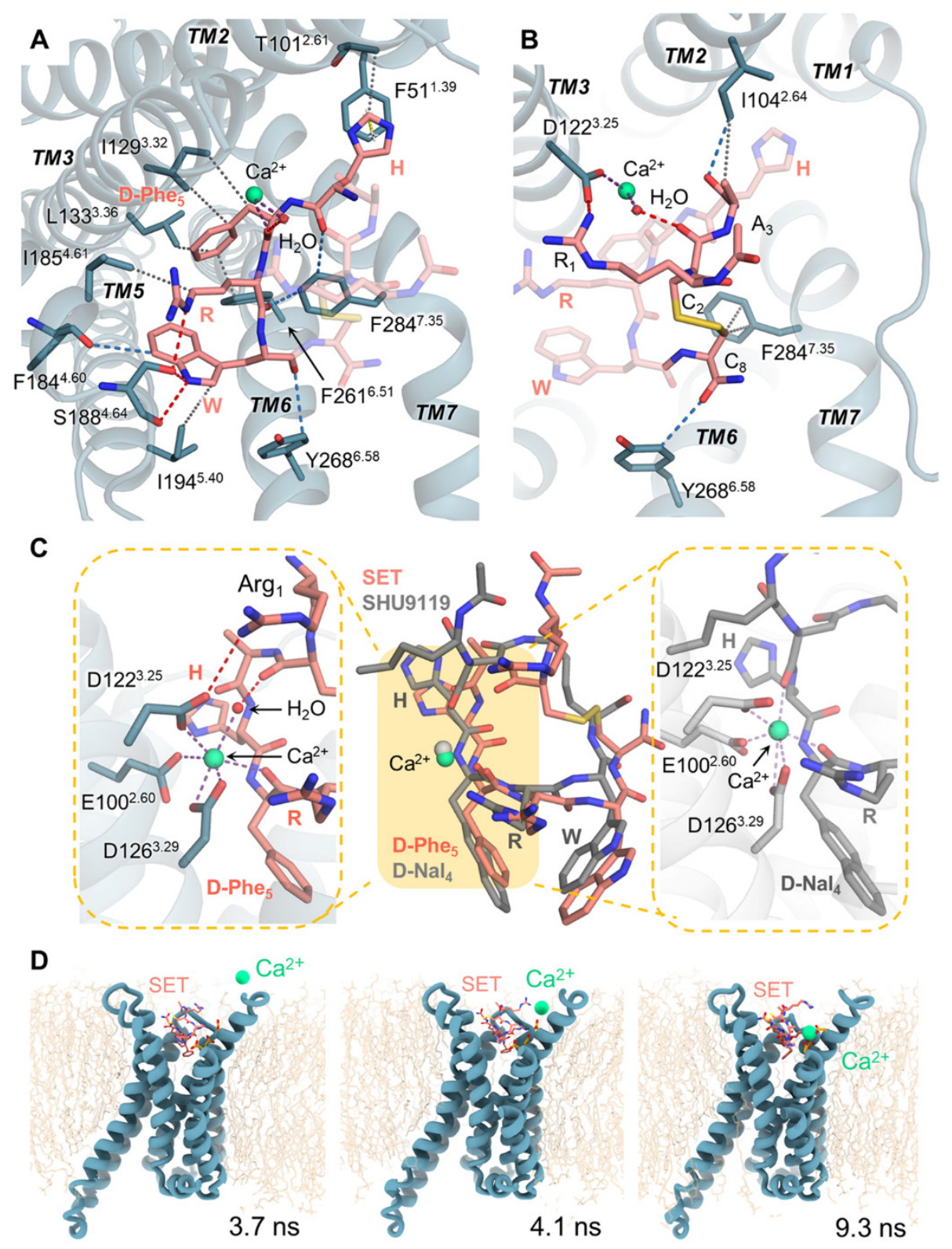

Fig. 3. Ligand accommodation within the MC4R binding pocket. (A and B) Setmelanotide interactions in the MC4R binding pocket. The receptor is presented in light blue, setmelanotide (SET) in pink, and $\mathrm{Ca}^{2+}$ in green. Dashed lines are colored according to the type of interactions, with hydrogen bonds in red, hydrophobic interactions in grey, $\mathrm{CH}-\mathrm{O}$ in blue, and $\mathrm{Ca}^{2+}$ coordination in purple. $\pi-\pi$ stacking is indicated by an asterisk. Interactions with HFRW motif are in (A) and with non-conserved residues in (B). (C) A comparison of the $\mathrm{Ca}^{2+}$ coordination in the presence of setmelanotide (agonist, pink, left) and SHU9119 (antagonist, grey, right PDB 6W25). Superposition is of the agonist and antagonist is in the middle. The receptor is presented as a cartoon with active conformation in light blue and inactive in grey. $\mathrm{Ca}^{2+}$ ion is in green for the active and grey for the inactive structure. (D) Snapshots of the molecular dynamics equilibration steps after 3.7, 4.1 and $9.3 \mathrm{~ns}$ (molecular dynamics run with setmelanotide, replica 1) showing the $\mathrm{Ca}^{2+}$ ion (green sphere) entering the ion binding pocket (yellow licorice side chains, showing residues $\mathrm{D} 122^{3.25}, \mathrm{D} 126^{3.29}$ and E100 2.60) of the MC4R receptor (light blue cartoon). Setmelanotide shown in pink, the membrane lipids in cream. In the starting configuration of all the simulations, $\mathrm{Ca}^{2+}$ was positioned in the intra and extra cellular water layers, leaving the $\mathrm{Ca}^{2+}$ binding site free. Out of a total cumulative simulation time of $2 \mu \mathrm{s}, \mathrm{Ca}^{2+}$ was found in the MC4R-bound position for $\sim 1.8 \mu \mathrm{s}$ and, once binding was established, the ion remained inside the binding pocket throughout the simulations performed (fig. S5, C and D). 

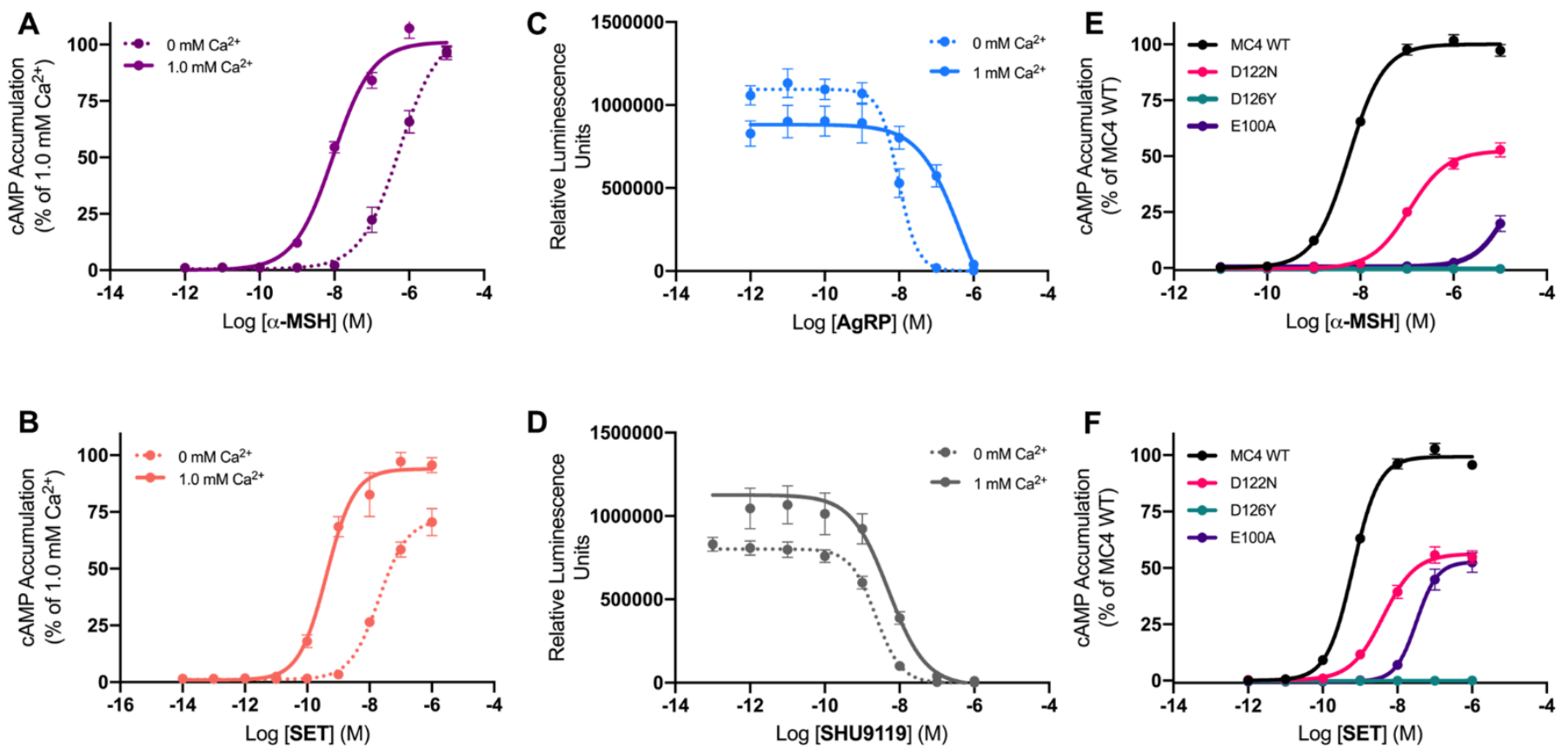

Fig. 4. $\mathrm{Ca}^{2+}$ acts as a cofactor for MC4R activation. ( $\mathrm{A}$ and $\mathrm{B}$ ) Dose response curves for the agonists $\alpha-\mathrm{MSH}(\mathrm{A})$ and setmelanotide (B) in the absence and presence of $1 \mathrm{mM} \mathrm{Ca}^{2+}$. The absence of $\mathrm{Ca}^{2+}$ is indicated with a dashed line. Data represented as mean \pm SEM from 3 independent experiments done in triplicate. (C and D) Competition assays of antagonists AgRP (C) and SHU9119 (D) with $\alpha$-MSH in the absence and presence of $1 \mathrm{mM} \mathrm{Ca}^{2+}$. Assays are calculated as the decrease in cAMP production in the presence of increasing dose of the antagonists. Experiments were conducted in the presence of $1 \mu \mathrm{M} \alpha-\mathrm{MSH}$. Data represented as mean \pm SEM from 3 independent experiments done in triplicate. $\left(\mathrm{E}\right.$ and $\mathrm{F}$ ) Mutations in residues involving $\mathrm{Ca}^{2+}$ coordination significantly reduce receptor's activation through $\alpha-\mathrm{MSH}(\mathrm{E})$ and setmelanotide $(\mathrm{F})$. Dose response curves for the agonists indicate elevation in cAMP production and are represented as mean \pm SEM from 3 independent experiments done in triplicate. Cell cytometry analysis indicating surface expression of wild-type and mutants is in fig. S8D. Mutant dependence on $\mathrm{Ca}^{2+}$ is in fig. S8, $\mathrm{E}$ and $\mathrm{F}$. 

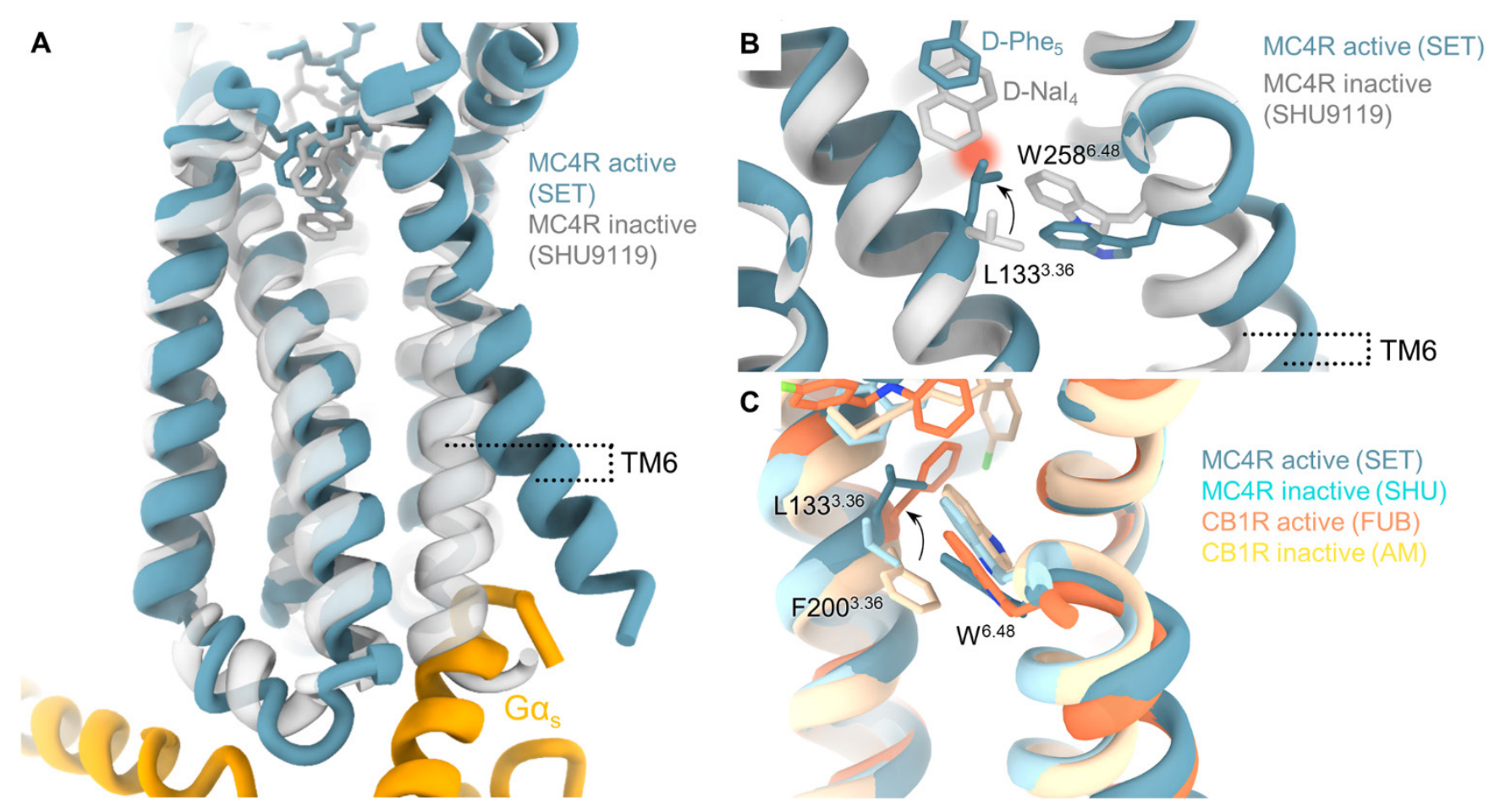

Fig. 5. MC4R activation switch. (A) Superposition of the MC4R active complex (blue) with an antagonist bound receptor (SHU9119, PDB 6W25, grey). Setmelanotide (SET, blue) and SHU9119 (grey) bound at the MC4R canonical pocket differentially interact with L1333.36 that composes the switch that controls receptor conformation. The outward movement of TM6 is indicated by black dashed lines, $\mathrm{G} \alpha_{s}$ is in yellow. (B) The bulky D-Nal 4 moiety in SHU9119 stabilizes the inactive switch conformation (grey), by which L1333.36 is stacked upon W2586.48. The D-Phe 5 moiety in setmelanotide contributes to an alternative rotamer, releasing W2586.48 which enables the outward movement of TM6 to allow the accommodation of $\mathrm{G} \alpha_{\mathrm{s}}$ and receptor activation (blue). The arrow indicates switch alternation from the inactive to the active state. (C) Superposition of MC4R activation switch (active - blue, inactive - light cyan) with a classical 'toggle twin switch' of CB1R (PDB 6N4B and 5TGZ, for active - orange, and inactive - light yellow conformations, respectively). The comparison between the two switches indicates a similar conformation of the two switches despite the difference in the identity of the switch residues. In MC4R the switch is composed of L1333.36 and W2586.48, whereas the classical switch in CB1R is composed of F2003.36 and W3566.48. 
A

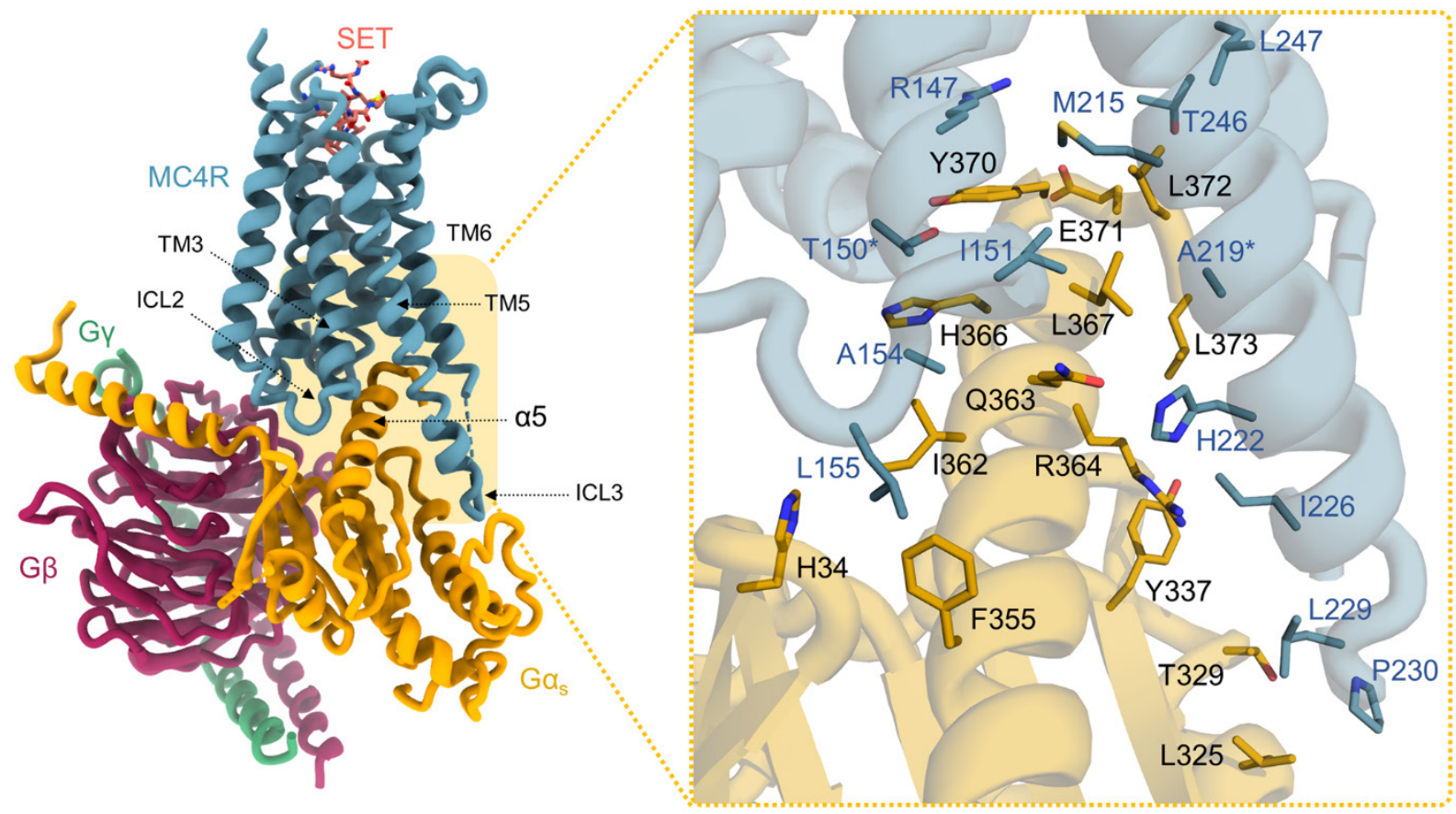

B

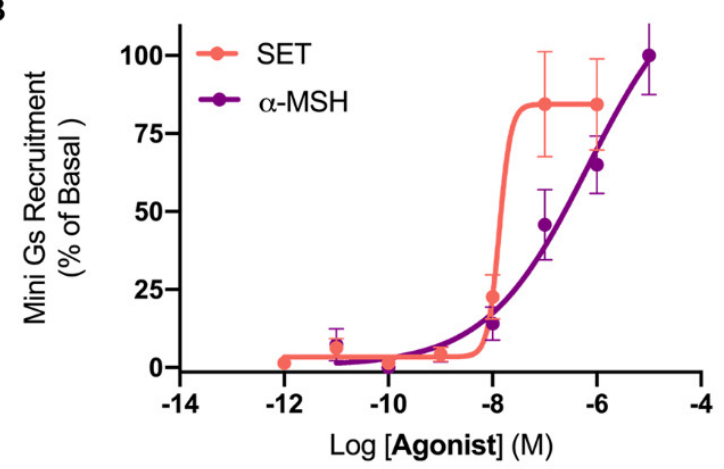

C

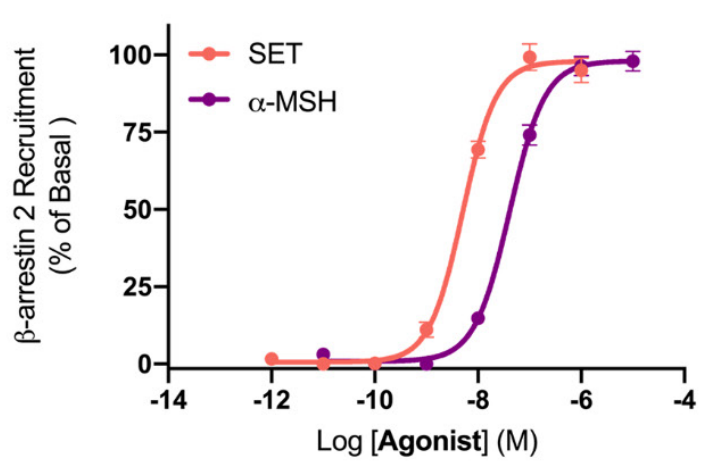

Fig. 6. MC4R G-protein coupling and biased signaling. (A) Analysis of residues in MC4R involved in $\mathrm{G}_{\mathrm{s}}$ recruitment. Residues in MC4R which are discussed in the main text are highlighted with an asterisk. A full description of interaction is provided in fig. S10. (B) Mini- $\mathrm{G}_{\mathrm{s}}$ recruitment upon setmelanotide and $\alpha-\mathrm{MSH}$ binding. Recruitment was monitored by nano-luciferase complementation using an MC4R-LgBit and a mini-G $\mathrm{G}_{\mathrm{s}}$ smBit. (C) $\beta$-arrestin 2 recruitment to MC4R. $\beta$-arrestin 2 was monitored by nano-luciferase complementation using an MC4R-LgBit and $\beta$-arrestin 2-smBit in HEK293 cells and plotted as a change in luciferase over time. For both (B) and (C), Y-axis is presented as a percent of basal as plotted in dose response curves for the agonists indicated and are represented as mean \pm SEM from 3 independent experiments done in triplicate. Analysis in the absence and presence of $\mathrm{Ca}^{2+}$ is provided in fig. S6, $\mathrm{K}$ and $\mathrm{L}$. 